\title{
Low Density Lipoprotein Receptor and 3-Hydroxy-3-Methylglutaryl Coenzyme A Reductase Gene Expression in Human Mononuclear Leukocytes Is Regulated Coordinately and Parallels Gene Expression in Human Liver
}

\author{
Elizabeth E. Powell and Paulus A. Kroon \\ Department of Biochemistry, The University of Queensland, Brisbane, Queensland 4072, Australia
}

\begin{abstract}
The liver plays a key regulatory role in cholesterol metabolism. Two proteins are central in this role; the LDL receptor and 3-hydroxy-3-methylglutaryl CoA reductase (HMG CoA reductase ), the rate-limiting enzyme in cholesterol biosynthesis. In the current investigation, we have used a sensitive nonradioactive method to study the regulation of $L D L$ receptor and HMG CoA reductase mRNA levels in liver biopsy samples and freshly isolated mononuclear leukocytes from 13 patients who underwent cholecystectomy for gallstones. mRNA copy numbers were determined by PCR amplification of reversetranscribed RNA using synthetic RNA as an internal standard. Incorporation of digoxigenin-11-dUTP during amplification allowed direct detection and quantitation of mRNA levels by chemiluminescence. These experiments showed that the average number of LDL receptor $\mathrm{mRNA}$ molecules in liver $(\mathbf{2 1} \pm 3$ $\times 10^{4} / \mu \mathrm{g}$ of RNA $)$ and mononuclear leukocytes $\left(24 \pm 3 \times 10^{4} /\right.$ $\mu \mathrm{g}$ of RNA) are indistinguishable, whereas the number of HMG CoA reductase molecules in liver $\left(107 \pm 15 \times 10^{4} / \mu \mathrm{g}\right.$ of RNA) is smaller than that in mononuclear leukocytes $(158 \pm 21$ $\times 10^{4} / \mu$ g of RNA, $\left.P<0.05\right)$. These numbers correspond to an average of 1-6 copies of $L D L$ receptor $M R N A$ and 5-42 copies of HMG CoA reductase mRNA per cell. There was a significant correlation between the numbers of $L D L$ receptor $(P$ $=0.0005)$ and HMG CoA reductase $(P=0.003)$ mRNA molecules in liver and mononuclear leukocytes. Furthermore, the numbers of copies of HMG CoA reductase and LDL receptor mRNA were correlated with each other in both liver $(P=0.02)$ and mononuclear leukocytes $(P=0.01)$, consistent with coordinate regulation. These data demonstrate that the mechanisms which regulate mRNA levels in liver and mononuclear cells are similar and suggest that freshly isolated mononuclear cells can be used to predict HMG CoA reductase and LDL receptor mRNA levels in liver. (J. Clin. Invest. 1994. 93:2168-2174.) Key words: low density lipoprotein receptor $-\mathrm{HMG}$ CoA reductase $\cdot$ gene expression $\cdot$ polymerase chain reaction $\bullet$ messenger RNA quantification
\end{abstract}

\section{Introduction}

The liver plays a central role in cholesterol metabolism, integrating lipoprotein-dependent cholesterol fluxes and the enterohepatic circulation of bile acids and cholesterol (1). Much of

Address correspondence to P. A. Kroon, Department of Biochemistry, The University of Queensland, Brisbane, Queensland 4072, Australia. Received for publication 17 July 1993 and in revised form 8 September 1993.

J. Clin. Invest.

(c) The American Society for Clinical Investigation, Inc.

0021-9738/94/05/2168/07 \$2.00

Volume 93, May 1994, 2168-2174 our current knowledge about how the hepatocyte achieves this is based on experiments with cultured cells. These studies have shown that cells, including hepatocytes, respond to cholesterol influx and efflux by regulating the activities of 3-hydroxy-3methylglutaryl CoA reductase (HMG CoA reductase),${ }^{1}$ the rate-limiting enzyme in cholesterol biosynthesis, and of the LDL receptor (2). These activities are regulated coordinately and act to maintain intracellular cholesterol levels within narrow limits. The promoters of the HMG CoA reductase and LDL receptor genes contain sterol-responsive elements which are believed to be responsible for the coordinate nature of these regulatory processes ( 3 ).

Recent studies have begun to focus on the in vivo regulation of HMG CoA reductase and the LDL receptor in human liver. However such studies are often hampered by the difficulty in obtaining human liver samples. One readily accessible source of cells that are exposed to the same external environment as hepatocytes is circulating mononuclear leukocytes. Since the basic regulatory mechanisms in liver and mononuclear leukocytes are similar, we hypothesized that the expression of LDL receptor and HMG CoA reductase genes in these cells may occur in parallel and that the measurement of gene expression in human mononuclear leukocytes may be predictive of gene expression in liver.

We have recently adapted a method of Wang et al. (4) to quantitate mRNA levels in small tissue samples available from in vivo sources $(5)$. We used this technique in the present study to examine the relationship between LDL receptor and HMG CoA reductase mRNA levels in the human liver and in peripheral blood mononuclear cells as a measure of gene expression in these cells.

\section{Methods}

Subjects and sample collection. The study comprised 13 patients who underwent cholecystectomy for symptomatic gallstones. Individual characteristics including lipid parameters and use of estrogen/progesterone values are summarized in Table I. All subjects were well at the time of the study and had no additional medical problems apart from mild systemic hypertension in patients 3 and 5 . Full blood counts were normal with the exception of one subject who had a mild increase in polymorphonuclear cell count. Three of the nine women were taking estrogen and progesterone preparations. Informed written consent was obtained from each patient before surgery, and the study protocol was approved by the Royal Brisbane Hospital Ethics Committee.

Surgery was performed after an 8-h fast. Immediately before induction of anesthesia, venous blood $(10 \mathrm{ml})$ was collected for the isolation of mononuclear cells and determination of serum lipoproteins. After the abdomen was opened, a small wedge or 2-cm tru-cut biopsy was taken from the liver. Half of this sample was placed immediately in 1.5 $\mathrm{ml}$ of a $4 \mathrm{M}$ guanidine isothiocyanate solution (4 M guanidinium isothiocyanate, $20 \mathrm{mM}$ sodium acetate, $\mathrm{pH} 5.2,0.1 \mathrm{mM}$ DTT, $0.5 \% \mathrm{~N}$ lauryl sarcosine) and homogenized in a microcentrifuge tube with a

1. Abbreviations used in this paper: DIG, digoxigenin-11-dUTP; HMG CoA reductase, 3-hydroxy-3-methylglutaryl CoA reductase. 
Table I. Characteristics of the Cholecystectomy Patients

\begin{tabular}{|c|c|c|c|c|c|c|c|c|c|}
\hline Patient & Sex & Age & Weight & Chol & TG & LDL-C & apo B & HDL-C & Steroids \\
\hline & & $y r$ & $k g$ & $\mathrm{mmol} / \mathrm{liter}$ & $\mathrm{mmol} / \mathrm{liter}$ & $\mathrm{mmol} / \mathrm{liter}$ & g/liter & $\mathrm{mmol} / \mathrm{liter}$ & \\
\hline 1 & $\mathrm{~F}$ & 66 & 66 & 5 & 1.47 & 3.4 & 1.03 & 0.9 & \\
\hline 2 & $\mathrm{~F}$ & 60 & 65.7 & 5.2 & 1.09 & 2.9 & 0.76 & 1.8 & Estrogen, progesterone \\
\hline 3 & $\mathrm{~F}$ & 60 & 86.5 & 9 & 1.6 & 6.5 & 1.3 & 1.81 & Estrogen \\
\hline 4 & $\mathrm{~F}$ & 39 & 90.4 & 5.5 & 1.05 & 4 & 0.87 & 1 & \\
\hline 5 & $\mathbf{M}^{*}$ & 57 & 60 & 4.9 & 1.8 & 3.1 & 0.86 & 0.95 & \\
\hline 6 & $\mathbf{F}$ & 31 & 66 & 6 & 1.09 & 4.5 & 0.92 & 0.98 & Estrogen \\
\hline 7 & $\mathrm{~F}$ & 48 & 70.5 & 6.7 & 1.23 & 4.9 & 1.09 & 1.2 & \\
\hline 8 & $\mathrm{~F}$ & 59 & 77 & 3.8 & 1.62 & 2.2 & 0.67 & 0.89 & \\
\hline 9 & $\mathrm{~F}$ & 68 & 62.7 & 7.3 & 1.26 & 5.4 & 1.09 & 1.3 & \\
\hline 10 & $F$ & 67 & 70.5 & 5.4 & 0.92 & 3.7 & 0.93 & 1.3 & \\
\hline 11 & $\mathbf{M}$ & 62 & 77.4 & 5.2 & 2.32 & 3.2 & 0.96 & 0.93 & \\
\hline 12 & $\mathbf{M}^{\ddagger}$ & 36 & 109 & 8.2 & 7.86 & NC & 2.17 & 0.59 & \\
\hline 13 & $\mathbf{M}^{\ddagger}$ & 40 & 85 & 5 & 3.51 & 2.7 & 1.14 & 0.72 & \\
\hline
\end{tabular}

To convert cholesterol values to milligrams per deciliter, multiply by 38.6 . To convert triglyceride values to milligrams per deciliter, multiply by 88.5. * Mononuclear leukocytes were not isolated for this patient. ${ }^{\ddagger}$ Liver biopsy sample too small to be used. Chol, cholesterol; $T G$, triglyceride; $L D L-C$, LDL cholesterol (calculated); $H D L-C$, HDL cholesterol; $N C$, not calculated because conditions for the Friedewald equation were not satisfied.

hand-held pestle. After centrifugation in a microcentrifuge (Heraeus; Sepatech $\mathrm{GmbH}$, Osterode, Germany) at $12,000 \mathrm{rpm}$ for $10 \mathrm{~min}$, the supernatant was removed and frozen immediately in liquid nitrogen. Samples were stored at $-70^{\circ} \mathrm{C}$ until required. Examination of the remainder of the liver biopsy samples showed normal histology with the following exceptions: one subject had pathological findings consistent with steatohepatitis, and two subjects had a moderate degree of fatty infiltration of the liver.

Mononuclear cells were isolated by centrifugation of whole blood on a Ficoll gradient as described previously (6). Analysis of several samples by flow cytometry and differential cell counting revealed a cell population that consisted of $85-90 \%$ lymphocytes. The mononuclear leukocyte preparations were lysed immediately in $4 \mathrm{M}$ guanidinium isothiocyanate, frozen in liquid nitrogen, and stored at $-70^{\circ} \mathrm{C}$ until required.

$R N A$ preparation. Total cellular RNA was prepared from the mononuclear leukocytes and liver samples by centrifugation of the $4 \mathrm{M}$ guanidinium isothiocyanate extracts through a $5.7 \mathrm{M}$ cesium chloride cushion as described previously (5). Mononuclear leukocyte RNA pellets were resuspended in $90 \mu \mathrm{l}$ TES buffer ( $10 \mathrm{mM}$ Tris $\mathrm{HCl}$, pH 7.4, $5 \mathrm{mM}$ EDTA, $1 \%$ SDS), precipitated twice with 0.1 vol $3 \mathrm{M}$ sodium acetate/ $2.5 \mathrm{vol}$ ethanol, and finally resuspended in $10 \mu \mathrm{l}$ of sterile deionized water. The liver RNA pellets were resuspended in $200 \mu \mathrm{l}$ TES buffer, extracted with phenol/chloroform/isoamyl alcohol (1:0.95:0.05, vol/ $\mathrm{vol})$, then with chloroform/isoamyl alcohol $(0.95: 0.05 \mathrm{vol} / \mathrm{vol})$, and finally resuspended in $10 \mu \mathrm{l}$ of sterile deionized water. The RNA concentration was measured spectrophotometrically at $260 \mathrm{~nm}$. All RNA preparations had an $A_{260} / A_{280}$ ratio of $>1.8$. Analysis of RNA by agarose $(1.5 \%)$ gel electrophoresis in the presence of formaldehyde showed clear undegraded $18 \mathrm{~S}$ and $28 \mathrm{~S}$ bands.

PCR amplification with a nonisotopic label. Aliquots of total cellular RNA (up to $120 \mathrm{ng}$ ) were reverse transcribed into cDNA in the presence of $10^{4}$ molecules of AW109 cRNA (Perkin-Elmer Cetus Instruments, Norwalk, CT) as an internal standard. AW109 cRNA contains primer sites separated by $250-300$ bp for a number of biologically important gene products including the LDL receptor and HMG CoA reductase (Fig. 1). An RNA-PCR kit (Perkin-Elmer Cetus Instruments) was used for this reaction according to procedures included, except that the concentration of dTTP was reduced from 1 to 0.975 $\mathrm{mM}$ to allow the incorporation of digoxigenin-11-dUTP (DIG) (Boehringer Mannheim Corp., Indianapolis, IN) as a nonisotopic label dur- ing PCR amplification of the reverse-transcribed RNA. PCR was performed as described in procedures provided with the RNA-PCR kit, except that 14-25 $\mu \mathrm{M}$ DIG was included, and $10 \mu \mathrm{l}$ of the reverse transcription reaction mixture was used in a total reaction volume of $50 \mu \mathrm{l}$. A total of $15 \mathrm{pmol}$ each of $5^{\prime}$ and $3^{\prime} \mathrm{LDL}$ receptor or HMG CoA reductase primers was added to the PCR mixture. The primer sequences are shown in Table II. The mixture was overlaid with $20 \mu \mathrm{l}$ of Nujol mineral oil (Cetus Corp., Berkeley, CA) and amplified with a fast thermal sequencer (FTS-1; Corbet Research, Sydney, Australia) for 25 cycles. The amplification profile involved denaturation at $95^{\circ} \mathrm{C}$ for $30 \mathrm{~s}$, primer annealing at $55^{\circ} \mathrm{C}$ for $30 \mathrm{~s}$, and extension at $72^{\circ} \mathrm{C}$ for $1 \mathrm{~min}$.

PCR product detection by chemiluminescence. $10 \mu \mathrm{l}$ of each $\mathrm{PCR}$ reaction mixture was size fractionated by electrophoresis on $3 \%$ agarose (Pharmacia LKB Biotechnology Inc., Piscataway, NJ) gels $(10 \mathrm{~cm} \times 7$ $\mathrm{cm}$ ) in Tris/acetate buffer, and transferred to a nylon membrane (Boehringer Mannheim Corp.) by blotting for $3 \mathrm{~h}$ in $10 \times \mathrm{SSC}(20 \times \mathrm{SSC}: 3 \mathrm{M}$ sodium chloride, $0.3 \mathrm{M}$ sodium citrate, $\mathrm{pH} 7$ ). The blot was baked under vacuum at $120^{\circ} \mathrm{C}$ for $20 \mathrm{~min}$ and rinsed in $2 \times \mathrm{SSC}$. Detection of the PCR products was performed directly on the nylon membrane using an antidigoxigenin antibody conjugated to alkaline phosphatase (Boehringer Mannheim Corp.). The protocol provided with the reagents was followed directly. Chemiluminescent detection of the antibody conjugate was performed by incubating the membrane for $5 \mathrm{~min}$ in a solution of disodium 3-(4-methoxyspiro[1,2-dioxethane-3,2'tricyclo $\left\{3.3 .1 .1^{3,7}\right\}$ decan $\left.]-4-y l\right)$ phenyl phosphate $(100 \mu \mathrm{g} / \mathrm{ml}$ in 0.1 $\mathrm{M}$ Tris $\mathrm{HCl}, 0.1 \mathrm{M}$ sodium chloride, $50 \mathrm{mM}$ magnesium chloride, $\mathrm{pH}$ 9.5) (Boehringer Mannheim Corp.). Sharp distinct signals were obtained after exposure for 2-10 min to x-ray film (Agfa Curix MR4).

Quantitation. Each pair of signals corresponding to the target mRNA and the internal control was scanned by a laser densitometer (rapid electrophoresis analyzer; Helena Laboratories, Beaumont, TX). Quantitation of the target mRNA was performed by comparison with the cRNA internal standard and expressed per microgram of total cellular RNA. We have shown previously that this approach leads to a linear relationship between RNA concentration and mRNA copy number. Integration of peak areas was performed by curve-fitting analysis (Peakfit; Jandel Scientific, Corte Madera, CA) as described previously. The concentration of LDL receptor or HMG CoA reductase mRNA was calculated from the relative sample and control peak areas and the known number of molecules of cRNA added to the PCR reaction (5). 


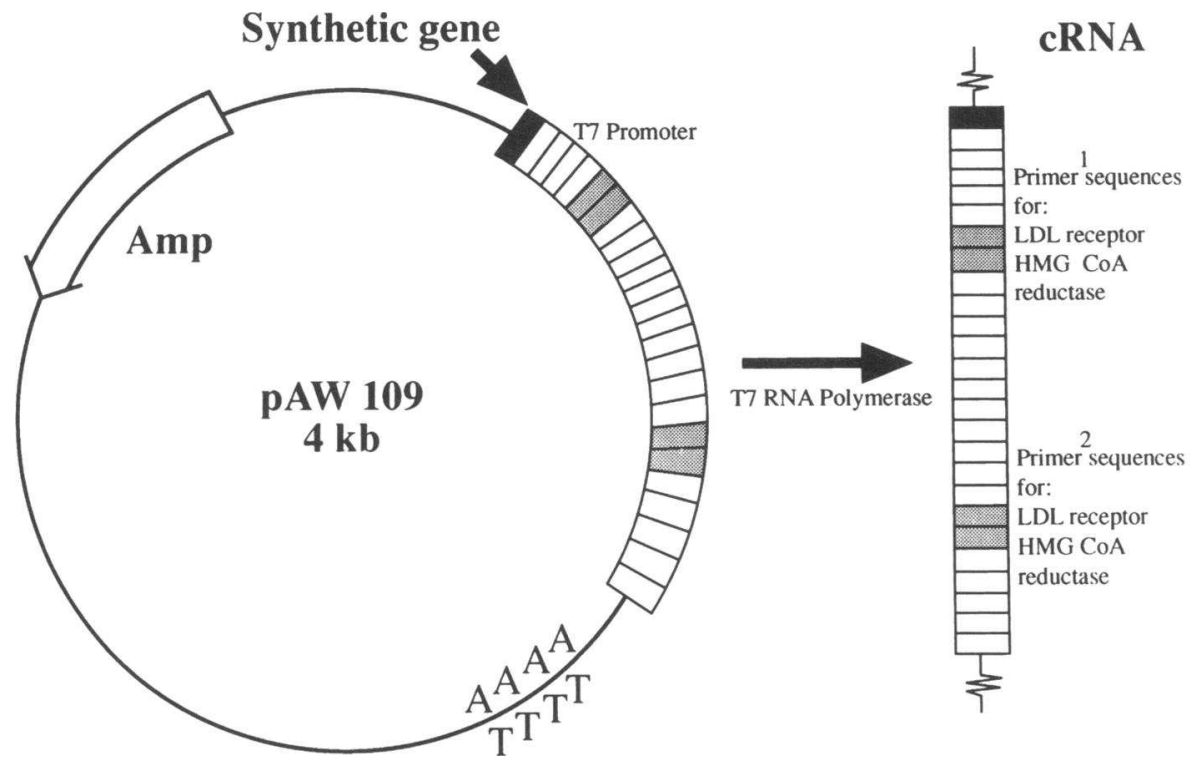

Figure 1. AW 109 cRNA is derived from the plasmid pAW 109, which contains sets of synthetic PCR primer sites for the LDL receptor and HMG CoA reductase as well as a number of other biologically important cDNAs.

The accuracy of this analysis depends on the relative intensity of the two bands, which was maintained at less than a ratio of $1: 2$ by changing the amount of cellular RNA used. We showed previously that the variation between duplicate measurements on tissue samples was $30 \%(5)$.

Serum lipids. Total serum cholesterol and triglycerides were determined on a centrifugal analyzer (Cobas Bio; Roche Diagnostics Systems, Hoffmann La Roche, Basel, Switzerland) using reagents from Boehringer Mannheim Corp. Standards were Pathonorm H from Nycomed Pharma (Oslo, Norway). HDL cholesterol was determined after precipitation with polyethylene glycol (7), using reagents from Boehringer Mannheim Corp. Standards were Seronorm from Nycomed Pharma. The concentration of LDL cholesterol was calculated using the Friedewald equation (8). Apo B was determined by end point immunoturbinometric assays (Orion Diagnostics, Espoo, Finland), using lyophilized pooled serum calibrated by radial immunodiffusion assay (Orion Diagnostics) as a standard.

Statistics. Data are presented as mean \pm SEM. Linear (Pearson) correlation coefficients were calculated using SAS program software (SAS Institute, Inc., Cary, NC).

\section{Results}

To quantitate mRNA levels in liver and mononuclear leukocytes, RNA was reverse transcribed in the presence of a known number of AW109 cRNA molecules. AW109 cRNA contains synthetic PCR primer sites for the LDL receptor and HMG CoA reductase and thus serves as a quantitative internal standard. The corresponding PCR primers are RNA specific. They span exon junctions, thus precluding the amplification of geno- mic DNA (4). PCR amplification of the reverse-transcribed RNA yielded products that differed sufficiently in size to allow separation by agarose gel electrophoresis. To confirm that the PCR products corresponded to the predicted LDL receptor and HMG CoA reductase fragments, they were digested with the restriction endonucleases AvalI and AvaI, respectively, and subjected to analysis by agarose gel electrophoresis (data not shown). The number and sizes of the fragments formed were consistent with those predicted from the known cDNA sequences (LDL receptor, 209 and 49 bp; HMG CoA reductase, 123,75 , and $48 \mathrm{bp}$ ). DIG was incorporated during amplification to allow detection of the PCR products on a Southern blot by enhanced chemiluminescence. Fig. 2 shows a representative Southern blot which was used to quantitate LDL receptor and HMG CoA reductase mRNA levels in liver and mononuclear cells from a single subject. To quantify these data, films were subjected to scanning densitometry, and relative areas were determined by curve-fit analysis. A comparison of the intensities of the chemiluminescent signal for fragments derived from native and AW109 cRNA permitted calculation of the number of LDL receptor and HMG CoA reductase mRNA molecules per microgram of total RNA (5).

The results of LDL receptor and HMG CoA reductase mRNA measurements in liver and mononuclear leukocytes from all of the subjects in the current study are summarized in Fig. 3. These data show that the average numbers of LDL receptor mRNA molecules in liver $\left(21 \pm 3 \times 10^{4} / \mu\right.$ g of RNA)

Table II. Primer Sequences for Amplification of Human and Synthetic RNA

\begin{tabular}{|c|c|c|c|c|}
\hline \multirow{2}{*}{$\begin{array}{l}\text { mRNA } \\
\text { species }\end{array}$} & \multirow[b]{2}{*}{ 5' Primers } & \multirow[b]{2}{*}{ 3' Primers } & \multicolumn{2}{|c|}{ Size of PCR product } \\
\hline & & & mRNA & cRNA \\
\hline & & & \multicolumn{2}{|c|}{$b p$} \\
\hline LDL-R & 5'-CAATGTCTCACCAAGCTCTG-3' & 5'-TCTGTCTCGAGGGGTAGCTG-3' & 258 & 301 \\
\hline HMG & 5'-TACCATGTCAGGGGTACGTC-3' & 5'-CAAGCCTAGAGACATAATCATC-3' & 246 & 303 \\
\hline
\end{tabular}




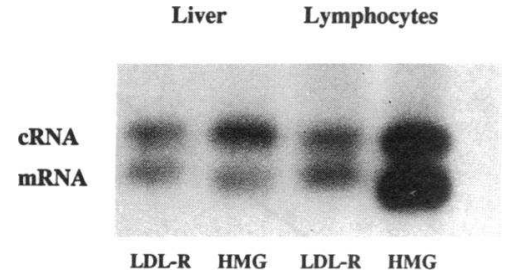

from liver and monoin the presence of $10^{4}$ copies of AW109 cRNA and subjected to 25 cycles of PCR amplification with LDL receptor or HMG CoA reductase primers. PCR products were separated by agarose gel electrophoresis, blotted onto nylon membrane, and detected by chemiluminescence as described in Methods. Lane 1, LDL receptor primers and liver RNA; lane 2, HMG CoA reductase primers and liver RNA; lane 3, LDL receptor primers and mononuclear cell RNA; lane 4, HMG CoA reductase primers and mononuclear cell RNA. The upper band in each case corresponds to cRNA, and the lower band corresponds to specific mRNA.

and mononuclear leukocytes $\left(24 \pm 3 \times 10^{4} / \mu \mathrm{g}\right.$ of RNA $)$ are indistinguishable, whereas the number of HMG CoA reductase molecules in liver $\left(107 \pm 15 \times 10^{4} / \mu \mathrm{g}\right.$ of RNA $)$ is smaller than that in mononuclear leukocytes $\left(158 \pm 21 \times 10^{4} / \mu \mathrm{g}\right.$ of RNA, $P$ $<0.05$ ). Assuming a ratio of RNA:DNA of 2.7:1 and a value of $5.5 \mathrm{pg}$ of DNA per diploid cell (9), our data show that mononuclear leukocytes and liver cells contain 1-6 copies of LDL receptor mRNA and 5-42 copies of HMG CoA reductase mRNA.

Although mononuclear leukocytes and liver differ enormously in their involvement in cholesterol metabolism, the underlying regulatory mechanisms for maintaining cellular cholesterol homeostasis are unlikely to differ significantly. Since both cell types appear to be exposed to a similar external milieu, we addressed the question as to whether LDL receptor and HMG CoA reductase mRNA levels in liver and mononu-

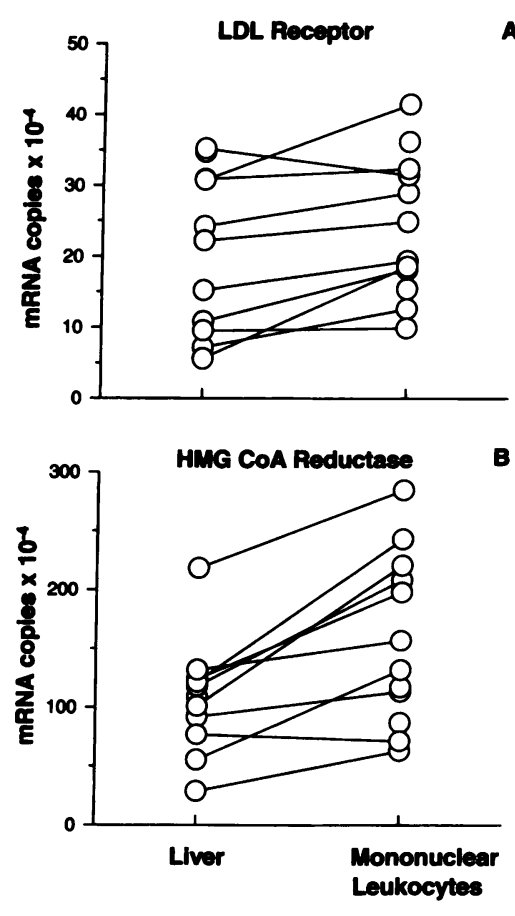

Figure 3. LDL receptor and HMG CoA reductase mRNA levels in liver and mononuclear leukocytes from all subjects. Data points for individual subjects for whom both liver and mononuclear leukocytes were available are connected. clear leukocytes were correlated. To compare gene expression in liver and mononuclear leukocytes, it was essential to minimize the time between venesection and liver biopsy. In the current studies, the maximum delay was $40 \mathrm{~min}$, with most samples collected within a 25 -min period. The first indication that mRNA levels in liver and mononuclear leukocytes from the same subject are related came from the results in Fig. 3. These data showed that subjects with low (high) LDL receptor or HMG CoA reductase mRNA levels in liver also tended to have low (high) levels in their mononuclear leukocytes. A more direct comparison of the number of LDL receptor mRNA molecules in liver versus mononuclear leukocytes for 10 of the patients in the current study, from whom both liver and mononuclear leukocytes were available, is shown in Fig. 4. Analysis of the data shows that these LDL receptor mRNA levels are highly correlated $(r=0.89, P=0.0005)$. A similar analysis of HMG CoA reductase mRNA levels in liver and mononuclear leukocytes (Fig. 5) demonstrates that HMG CoA reductase mRNA levels in liver and mononuclear leukocytes are also correlated $(r=0.83, P=0.003)$. These results show for the first time that changes in mRNA levels for both the LDL receptor and HMG CoA reductase in mononuclear leukocytes and liver occur in parallel and suggest that common regulatory steps exist to maintain this relationship.

A key feature of the regulation of LDL receptor and HMG CoA reductase mRNA levels is the existence of sterol-responsive elements within the promoters of both genes ( 3 ). Sterol-responsive elements are believed to be responsible for the coordinate transcriptional regulation mediated by sterols in cell culture (10). We addressed the question of whether the LDL receptor and HMG CoA reductase genes were regulated coordinately in vivo. Figs. 6 and 7 show the relationship between LDL receptor and HMG CoA reductase mRNA levels in liver and mononuclear leukocytes, respectively. These data are consistent with coordinate regulation in both the liver $(r=0.69, P$ $=0.02)$ and in mononuclear leukocytes $(r=0.68, P=0.01)$.

We analyzed the relationship between serum LDL and HDL cholesterol concentrations and the number of LDL re-

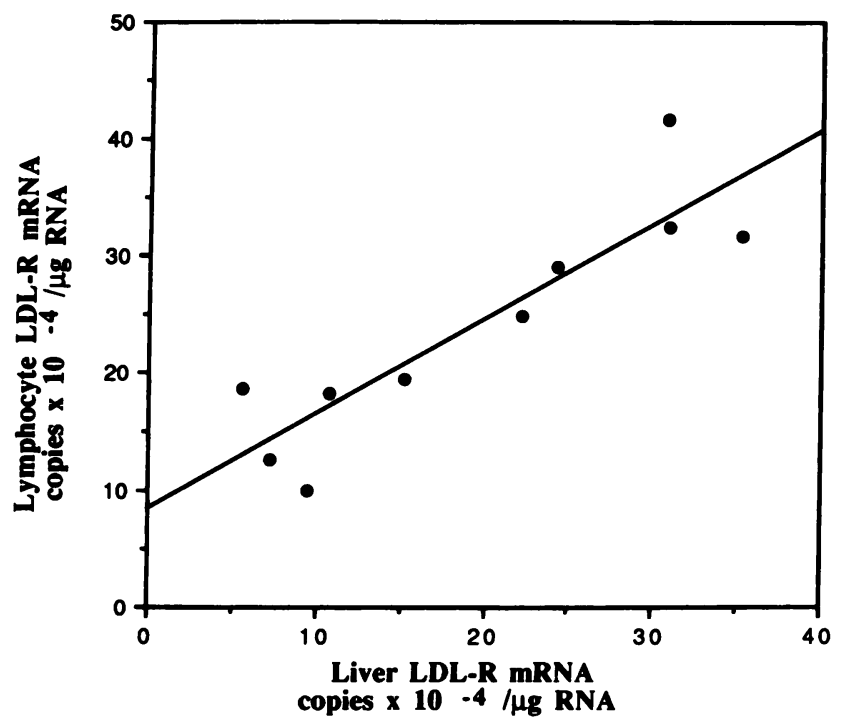

Figure 4. Correlation between LDL receptor mRNA levels from mononuclear leukocytes and liver $(r=0.89, P=0.0005)$. The line was obtained by linear regression analysis. 


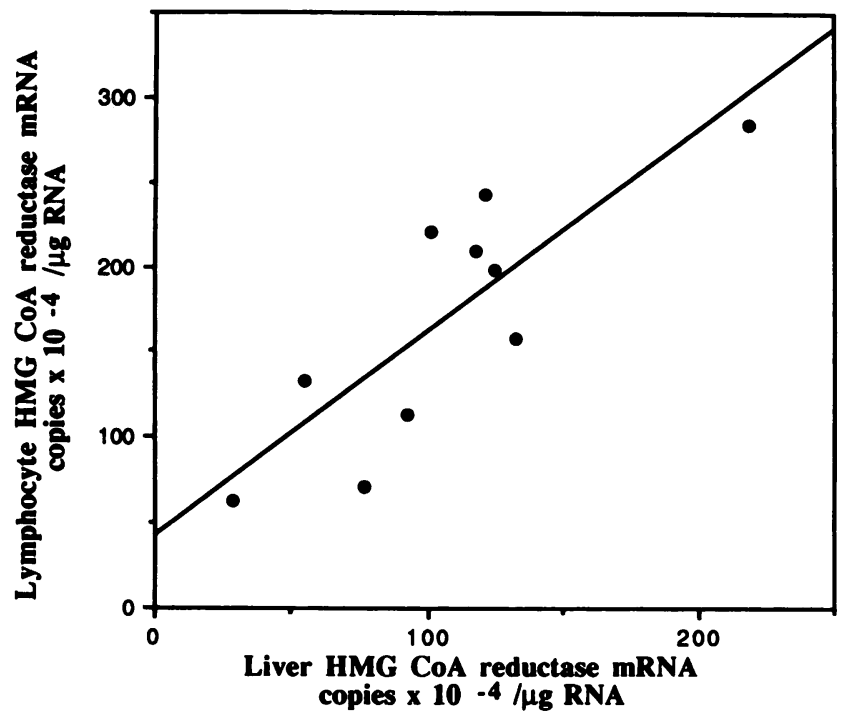

Figure 5. Correlation between HMG CoA reductase mRNA levels from mononuclear leukocytes and liver $(r=0.83, P=0.003)$. The line was obtained by linear regression analysis.

ceptor and HMG CoA reductase mRNA molecules. The relationship between total and LDL cholesterol and mRNA copies did not reach statistical significance. A significant but weak correlation was observed between the number of LDL receptor mRNA molecules per microgram of RNA and the concentration of serum HDL $(r=0.61, P<0.05)$. There was no relationship between mRNA levels and the subject's age or weight.

\section{Discussion}

The liver plays a central role in cholesterol and lipoprotein metabolism. However, its inaccessibility has made studies of its involvement in lipid metabolism difficult. This has led investigators to study more readily accessible cell types which may

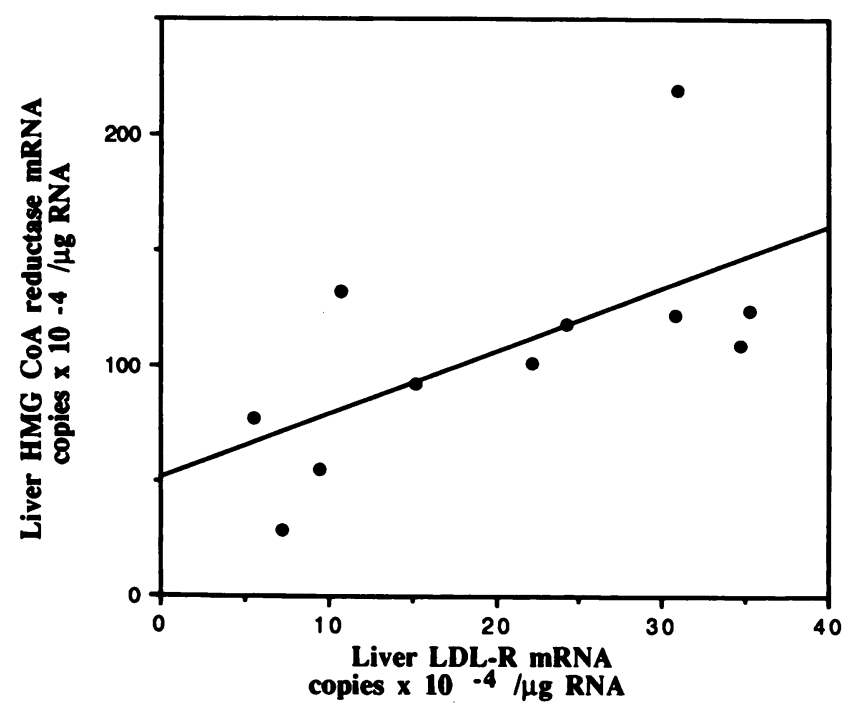

Figure 6. Correlation between LDL receptor and HMG CoA reductase mRNA levels in liver $(r=0.69, P=0.02)$. The line was obtained by linear regression analysis.

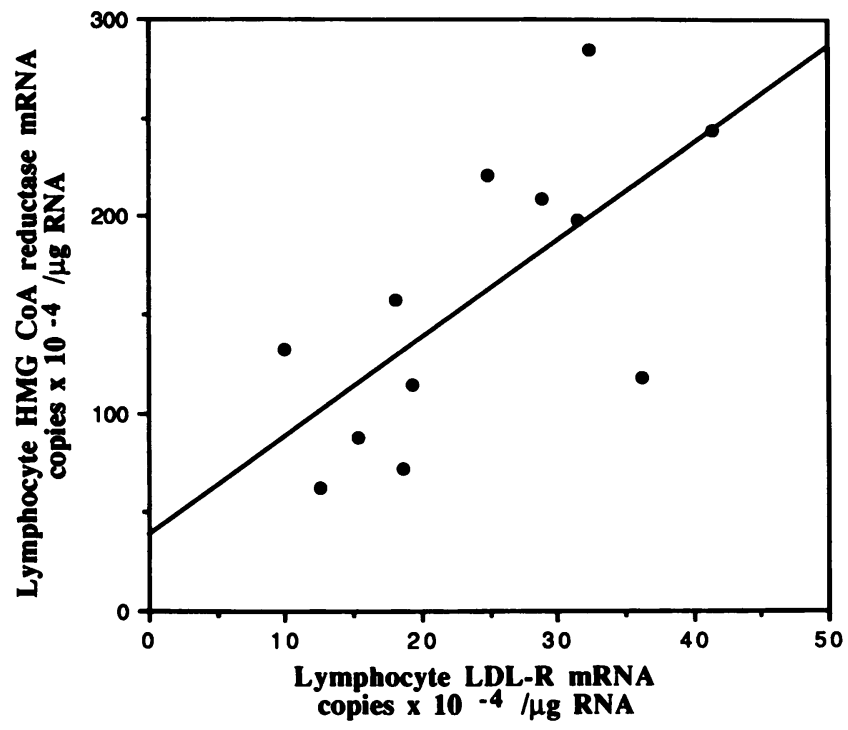

Figure 7. Correlation between LDL receptor and HMG CoA reductase mRNA levels in mononuclear leukocytes $(r=0.68, P=0.01)$.

The line was obtained by linear regression analysis.

reflect cholesterol metabolism in the liver. Particular attention has been focused on circulating mononuclear leukocytes (11, 12 ), although a direct correlation between the properties of liver and mononuclear leukocytes in the same subject has not been shown. In the current studies, we have addressed this issue and demonstrate for the first time that $(a)$ the expression of the LDL receptor and HMG CoA reductase genes in mononuclear leukocytes closely parallels expression in human liver, and $(b)$ that LDL receptor and HMG CoA reductase genes in both the liver and mononuclear leukocytes are expressed coordinately. We conclude that freshly isolated mononuclear leukocytes can be used to predict the level of expression of the HMG CoA reductase and LDL receptor genes in the liver and that the mechanisms which regulate gene expression in liver and mononuclear leukocytes are similar. We note, however, that the correlation between mRNA levels in liver and mononuclear cells involved mostly female patients $(9 / 10)$. While it is unlikely that this relationship is sex dependent, further studies are required to confirm this.

The close correlation between HMG CoA reductase and LDL receptor mRNA levels in mononuclear leukocytes and liver suggests that there is a common factor or process in the circulation which mediates regulation of these mRNAs. Hepatocytes are exposed to the vascular space through the fenestrated sinusoidal endothelium and therefore are exposed to the same milieu as mononuclear leukocytes in the circulation. However, because lymphocytes, the major cellular component of mononuclear cells, continually move between the vascular space, the spleen, and lymph nodes (13), such cells obtained at the time of venesection have a somewhat heterogeneous past.

A priori, the involvement of lipoprotein-derived sterol in the regulation of LDL receptor and HMG CoA reductase mRNAs appears likely. Sterol-mediated regulation of transcription has been demonstrated for both the LDL receptor and HMG CoA reductase genes and is due to the presence of cis-acting sterol-responsive elements in the $5^{\prime}$ flanking regions of these genes (3). LDL is the most abundant cholesterol esterrich lipoprotein in the circulation and is likely to provide a 
major contribution to the intracellular pool of regulatory sterol. Other lipoproteins that may contribute to this pool include VLDL remnants. VLDL remnants are cholesterol esterrich particles which have a high affinity for the LDL receptor because they contain multiple copies of apo E (2). VLDL remnants provide a significant flux of sterol through the liver; $\sim 60 \%$ of VLDL remnants is removed by the liver, while the remaining $40 \%$ is converted to $\operatorname{LDL}(14,15)$.

The relationship between LDL receptor protein levels and plasma cholesterol levels in humans has been addressed in several studies, with contrasting results. Mistry et al. (16) found no correlation between LDL receptor levels in mononuclear cells and the total or LDL cholesterol concentration in plasma. In contrast, Soutar et al. (17) demonstrated a statistically significant inverse correlation between hepatic LDL receptor protein and plasma LDL cholesterol concentrations in 10 cancer patients with low mean cholesterol concentrations. Similarly, a study of hepatic LDL receptor levels during fetal development showed an inverse correlation with plasma LDL concentrations (18).

Despite the fact that LDL is the major source of cholesterol in the circulation, the relationship between LDL cholesterol concentrations and gene expression is likely to be complex. Plasma LDL concentrations are determined by a combination of hepatic secretion of VLDL and hepatic LDL receptor-dependent removal of VLDL remnants and LDL from the circulation. In contrast, the intracellular concentration of regulatory sterol is dependent on the cellular influx and efflux of cholesterol. Because the mean concentration of circulating LDL in adults (2.8-3.9 mmol/liter depending on age) is much higher than the apparent $K_{\mathrm{d}}(18 \mathrm{nM}$, which is equivalent to 0.04 mmol cholesterol/liter) of LDL for the LDL receptor (19), receptor-mediated uptake of LDL is predicted to be proportional to the number of cellular LDL receptors and independent of the plasma LDL concentration. In the current study, contributions to cellular cholesterol pools by chylomicron remnants can be neglected because patients were fasted before surgery. Contributions by receptor-independent uptake, though smaller than receptor-dependent uptake, may depend on the plasma LDL concentration. Assuming that receptor-dependent uptake is dominant, the rate of influx of LDL cholesterol will be constant. To maintain cellular cholesterol homeostasis, this influx must be balanced by an efflux of cholesterol which may play a regulatory role. While efflux from the liver can be mediated by lipoprotein secretion and secretion of sterol into bile, these mechanisms are not shared with mononuclear cells.

We considered the possibility that efflux mediated by HDLdependent reverse cholesterol transport might be one such shared mechanism (20). In this way elevated HDL levels may increase the cholesterol efflux from mononuclear leukocytes and hepatocytes and thus increase LDL receptor and HMG CoA reductase mRNA levels. Contrary to our expectations, there was a significant, though weak $(P<0.05)$, inverse correlation between LDL receptor mRNA levels in both liver and mononuclear leukocytes and HDL cholesterol levels in this patient group. The mechanism responsible for the close correlation between $\mathrm{LDL}$ receptor and $\mathrm{HMG}$ CoA reductase mRNA levels in liver and mononuclear leukocytes therefore remains to be elucidated.

Coordinate regulation of $\mathrm{LDL}$ receptor and $\mathrm{HMG}$ CoA reductase mRNAs has been demonstrated clearly in cultured cells $(10,21)$. The question of in vivo coordinate regulation has been more controversial. Spady et al. (22) concluded that cholesterol synthesis and receptor-dependent removal of LDL by the liver are regulated independently. The current data are clearly inconsistent with this view, at least for mRNA levels. The number of copies of HMG CoA reductase and LDL receptor mRNA molecules is correlated in both mononuclear leukocytes and liver, consistent with the hypothesis that the HMG CoA reductase and LDL receptor genes are regulated coordinately. Although this is likely because of transcriptional regulation, the involvement of posttranscriptional regulatory steps cannot be excluded. Irrespective of the mechanisms involved, the current data suggest that liver cells and mononuclear leukocytes respond to an increased demand for cholesterol by increasing the number of copies of LDL receptor and HMG CoA reductase mRNA molecules simultaneously. Recent studies in which hepatic HMG CoA reductase and LDL receptor activities were measured in patients treated with pravastatin and in patients with Crohn's disease have demonstrated that the activities are also correlated $(23,24)$.

The current studies have provided the first measurement of the number of LDL receptor and HMG CoA reductase mRNA molecules in human mononuclear leukocytes and liver cells in vivo. Both liver and mononuclear leukocytes contained between one and six copies of LDL receptor mRNA per cell. A similar number of copies is present in the liver of nonhuman primates (25). The hepatic LDL receptor mRNA content in these animals was $1.2-2.4 \mathrm{pg} / \mu \mathrm{g}$ of RNA, which corresponds to approximately five copies of LDL receptor mRNA per cell. Significantly higher levels (40-80 copies of LDL receptor mRNA per cell) have been reported for rabbit hepatocytes (26). We surmise that this reflects interspecies differences in gene expression. A recent study has reported the use of solution hybridization to quantify LDL receptor and $\mathrm{HMG}$ CoA reductase mRNA copy numbers in cultured human fibroblasts and in the human hepatoma cell line HepG2 (21). In the presence of sterol designed to downregulate gene expression, HepG2 cells contained 17 copies of LDL receptor mRNA, while $<10$ copies (the lower limit of detection) of HMG CoA reductase were present. Under conditions of maximal upregulation, HepG2 cells contained 196 and 120 copies of LDL receptor and HMG CoA reductase mRNA, respectively. While a comparison of in vivo and cell culture experiments is difficult, these results do indicate that the copy numbers found in the liver in vivo reflect the repressed state more closely than the derepressed state.

After completion of this manuscript, a report by Rudling (27) demonstrated that LDL receptor and HMG CoA reductase mRNA levels are regulated coordinately in livers from mice fed a number of different diets. In agreement with our results, there was no correlation between plasma cholesterol concentrations and LDL receptor and $H M G$ CoA reductase mRNA levels.

\section{Acknowledgments}

We gratefully acknowledge the surgeons from the Hepatobiliary Unit at the Royal Brisbane Hospital for providing tissue samples for this study.

This work was supported by a grant from the National Heart Foundation of Australia. Elizabeth E. Powell was a recipient of a National Health \& Medical Research Council Medical Postgraduate Scholarship. 


\section{References}

1. Kroon, P. A., and E. E. Powell. 1992. Liver, lipoproteins and disease. I. Biochemistry of lipoprotein metabolism. J. Gastroenterol. Hepatol. 7:214-224.

2. Brown, M. S., and J. L. Goldstein. 1986. A receptor-mediated pathway for cholesterol homeostasis. Science (Wash. DC). 232:34-47.

3. Goldstein, J. L., and M. S. Brown. 1990. Regulation of the mevalonate pathway. Nature (Lond.). 343:425-430.

4. Wang, A. M., M. V. Doyle, and D. F. Mark. 1989. Quantitation of mRNA by the polymerase chain reaction. Proc. Natl. Acad. Sci. USA. 86:9717-9721.

5. Powell, E. E., and P. A. Kroon. 1992. Measurement of mRNA by quantitative PCR with a nonradioactive label. J. Lipid Res. 33:609-614.

6. Boyum, A. 1968. Isolation of mononuclear cells and granulocytes from human blood. Isolation of mononuclear cells by one centrifugation, and of granulocytes by combining centrifugation and sedimentation at $1 \mathrm{~g}$. Scand. J. Clin. Lab. Invest. 21 (Suppl. 97):77-89.

7. Allen, J. K., W. J. Hensley, A. V. Nicholls, and J. B. Whitfield. 1979. An enzymatic and centrifugal method for estimating high-density lipoprotein cholesterol. Clin. Chem. 25:325-327.

8. Friedewald, W. T., R. I. Levy, and D. S. Fredrickson. 1972. Estimation of the concentration of low-density lipoprotein cholesterol in plasma, without use of the preparative ultracentrifuge. Clin. Chim. Acta. 71:397-402.

9. Williams, D. L., T. C. Newman, G. S. Shelness, and D. A. Gorden. 1986. Measurement of apolipoprotein mRNA by DNA-excess solution hybridization with single-stranded probes. Methods Enzymol. 128:671-689.

10. Molowa, D. T., and G. M. Cimis. 1989. Co-ordinate regulation of lowdensity-lipoprotein receptor and 3-hydroxy-3-methylglutaryl-CoA reductase and synthase gene expression in HepG2 cells. Biochem. J. 260:731-736.

11. Cuthbert, J. A., D. W. Russell, and P. E. Lipsky. 1989. Regulation of low density lipoprotein receptor gene expression in human mononuclear leukocytes. J. Biol. Chem. 264:1298-1304.

12. Harwood, H. J., Jr., D. M. Bridge, and P. W. Stacpoole. 1987. In vivo regulation of human mononuclear leukocyte 3-hydroxy-3-methylglutaryl coenzyme A reductase. Studies in normal subjects. J. Clin. Invest. 79:1125-1132.

13. Roitt, I. M. 1991. Essential Immunology. Blackwell Scientific Publications Ltd., Oxford.

14. Egusa, G., W. F. Beltz, S. M. Grundy, and B. V. Howard. 1985. The influence of obesity on the metabolism of apolipoprotein B in humans. J. Clin. Invest. 76:596-603.

15. Kesäniemi, Y. A., W. F. Beltz, and S. M. Grundy. 1985. Comparison of metabolism of apolipoprotein B in normal subjects, obese patients, and patients with coronary heart disease. J. Clin. Invest. 76:586-595.

16. Mistry, P., N. E. Miller, M. Laker, W. R. Hazzard, and B. Lewis. 1981. Individual variation in the effects of dietary cholesterol on plasma lipoproteins and cellular cholesterol homeostasis in man. J. Clin. Invest. 67:493-502.

17. Soutar, A. K., K. Harders-Spengel, D. P. Wade, and B. L. Knight. 1986. Detection and quantitation of low density lipoprotein (LDL) receptors in human liver by ligand blotting, immunoblotting and radioimmunoassay. LDL receptor protein content is correlated with plasma LDL cholesterol concentration. J. Biol. Chem. 261:17127-17133.

18. Cai, H.-J., C.-L. Xie, Q. Chen, X.-Y. Chen, and Y.-H. Chen. 1991. The relationship between hepatic low-density lipoprotein receptor activity and serum cholesterol levels in the human fetus. Hepatology. 13:852-857.

19. Schneider, W. J., U. Beisiegel, J. L. Goldstein, and M. S. Brown. 1982. Purification of the low density lipoprotein receptor, an acidic glycoprotein of 164,000 molecular weight. J. Biol. Chem. 257:2664-2673.

20. Tall, A. R. 1990. Plasma high density lipoproteins. Metabolism and relationship to atherogenesis. J. Clin. Invest. 86:379-384.

21. Le Cras, T. D., E. Gherardi, and D. E. Bowyer. 1991. A sensitive RNase protection assay for the quantitation of the mRNAs for the LDL-R and HMG CoA reductase in human total RNA. Atherosclerosis. 90:81-90.

22. Spady, D. K., S. D. Turley, and J. M. Dietschy. 1985. Rates of low density lipoprotein uptake and cholesterol synthesis are regulated independently in the liver. J. Lipid Res. 26:465-472.

23. Reihner, E., M. Rudling, D. Stahlberg, L. Berglund, S. Ewerth, I. Bjorkhem, K. Einarsson, and B. Angelin. 1990. Influence of pravastatin, a specific inhibitor of HMG CoA reductase, on hepatic metabolism of cholesterol. $N$. Engl. J. Med. 323:224-227.

24. Akerlund, J., E. Reihner, B. Angelin, M. Rudling, S. Ewerth, I. Bjorkhem, and K. Einarsson. 1991. Hepatic metabolism of cholesterol in Crohn's disease. Effect of partial resection of ileum. Gasteroenterology. 100:1046-1053.

25. Sorci-Thomas, M., M. D. Wilson, F. L. Johnson, D. L. Williams, and L. L. Rudel. 1989. Studies on the expression of genes encoding apolipoproteins B100 and B48 and the low density lipoprotein receptor in nonhuman primates. J. Biol Chem. 264:9039-9045.

26. Ma, P. T. S., T. Yamamoto, J. L. Goldstein, and M. S. Brown. 1986. Increased mRNA for low density lipoprotein receptors in livers of rabbits treated with $\alpha$-ethinyl estradiol. Proc. Natl. Acad. Sci. USA. 83:792-796.

27. Rudling, M. 1992. Hepatic mRNA levels for the LDL receptor and HMG CoA reductase show coordinate regulation in vivo. J. Lipid Res. 33:493-501. 